\title{
Lab Animal is turning 45
}

Having recently joined Lab Animal as the new editor, I want to take this opportunity to introduce myself and say a few words about the journal. I am a neuroscientist by training and have spent the past 15 years studying the nervous system in a wide range of animals including snails, zebrafish, mice, rats and macaques. During the early years of my career, I worked primarily on anesthetized animals and spent little time in my institution's animal care facility. Like most graduate students, I was blissfully unaware of all the behind-thescenes effort that animal care staff carry out on a daily basis. As my interests turned towards animal behavior, I began working more closely with staff at various levels. Whether designing a novel water delivery system with technicians and facility managers, or developing a less invasive surgical procedure with a clinical veterinarian, the entire staff was always willing to go the extra mile to make sure that my animals were happy and healthy. After receiving so much support from the lab animal science community, I am thrilled to be serving you now as editor of Lab Animal.

This year marks Lab Animal's 45th year of publishing original research and editorial content that is important to the animal research community. With the speed of biomedical research moving faster now than ever, it is critical that members of our community have the latest knowledge of research, techniques and products that are vital to ensuring the welfare and efficient use of animals involved in research. As we move into a new year, we will focus the journal's efforts in four key areas.

First and foremost is reader engagement. Ultimately, Lab Animal's direction will be determined by the community of readers and authors that it serves. With this in mind, we invite you to reach out to us by emailing editors@labanimal.com with your comments on research articles, column ideas and anything else you think the journal can do to better support the lab animal science community. By publishing your comments and ideas (with your permission), we hope to further connect the community through a shared discourse.

Secondly, we plan to expand our content on practical topics for veterinarians, technicians and facility managers who are on the front-lines of animal care and welfare. Lab Animal has always strived to provide useful hands-on information about techniques and methods, and we will encourage more people to share their knowledge with the community through new columns and short article formats that provide succinct and practical advice on common concerns.

Our third area of renewed focus will be on animal research policy and regulations. Veterinarians, technicians, facility managers, investigators and IACUC members all require up-to-date material about current trends in policies affecting animal research. Furthermore, because biomedical research is becoming more collaborative with labs working together across the globe, the research community needs an international perspective on its policies.

Finally, our last aim will be on animal research itself. We will focus on publishing articles of novel and cutting-edge research on animal care and welfare, as well as breakthroughs in other aspects of comparative medicine including animal models of human disease, virology and zoonosis. Advancements in animal welfare provide the backbone for biomedical research, and we hope that Lab Animal will remain one of the go-to journals for publishing findings in both areas.

We look forward to the year ahead of us and working together to bring the best research and most important news and information to the lab animal science community.

Dustin M. Graham, PhD Editor, Lab Animal 